Bangladesh J. Sci. Res. 29(1): 19-29, 2016 (June)

\title{
ANALYSIS OF DST TO PREDICT OIL SAND: A CASE STUDY OF KAILASHTILLA FIELD
}

\author{
Mohammad Amirul Islam*, A.S.M. Woobaidullah and Badrul Imam \\ Department of Geology, University of Dhaka, Dhaka-1000, Bangladesh
}

\begin{abstract}
Drill Stem Test (DST) describes the dynamic characteristic of the hydrocarbon bearing formation such as wellbore storage, skin effect, permeability, average reservoir pressure and reservoir boundary. The wellbore storage effect and average reservoir pressure help to predict the flowing phase from the reservoir. An effort has been made to analyze the DST conducted in the Kailashtilla field at the depth interval 3261 meter to 3266 meter in well KTL-7. Two sets of pressure profile have been recorded. First conditioning the well for an hour then performed drawdown following pressure build-up. The pressure signature of the buildup period and its derivative is plotted on semi-log and log-log coordinates to develop Horner and diagnostic plots, respectively. Wellbore storage, skin and transient flow effects have been observed in the DST analysis which is an indication of the hydrocarbon bearing reservoir in the zone of interest. The value of wellbore storage effect is low which predicts the flow of liquid hydrocarbon into the well bore from the reservoir. Average pressure of the investigated zone has been estimated which is higher than the water column pressure. The higher average reservoir pressure also authenticates the presence of oil reservoir.
\end{abstract}

Key words: Well log, DST, pressure buildup, wellbore storage, average reservoir pressure

\section{Introduction}

DST is one kind of well test which is performed to predict the hydrocarbon bearing zone and its characteristics (Ehlig et al. 1990). Results that can be obtained from well testing are a function of the range and the quality of the pressure and rate data available and of the approach used for their analysis. Consequently, at any given time, the extent and quality of an analysis are limited by the state-of-the-art in both data acquisition and analysis techniques (Earlougher 1977). As data improve, and better interpretation methods are developed, more and more useful information can be extracted from well test data (Ramey1992). One important ingredient of the integrated methodology was the realization, from experience, that, although reservoirs are different in terms of physical description (type of rock, depth, pressure, size, type of fluid, fluid content, etc.), the number of possible dynamic behaviors of these reservoirs during a well test was limited (Miller $e t$ al. 1950). This is because a reservoir acts as a low-resolution filter, so that only high contrasts in reservoir properties can appear in the output signal. Furthermore, these dynamic behaviors were obtained from the combination of three components that dominate at different times during the test, namely (i) the basic dynamic behavior of the reservoir, during middle times, which is usually

*Author for correspondence: <mohamm1978@gmail.com>. 
the same for all the wells in a given reservoir, (ii) near-wellbore effects, at early times, due to the well completion that may vary from well to well, or from test to test and (iii) boundary effects, at late times, determined by the nature of the reservoir boundaries (the same for all the wells in a given reservoir) and by the distance from the well to these boundaries (which may differ from well to well) (Gringarten et al. 1979).

\section{Field description}

The Kailastila field is located 13 kilometers south of Sylhet field and it is about 250 kilometers north-east of Dhaka. The Kailastila field lies in the central part of the Surma Basin, and on the western margin of the Tripura high. The Kailastila structure was delineated by Shell in 1960 on the basis of single-fold analog seismic data acquired in late 1950's. The structure is a four way dip closure. The KTL-1 was drilled in 1961 to a depth of $4138 \mathrm{~m}$ and encountered four gas sands. Subsequently five more wells, KTL-2 to KTL-6 were drilled since then. The Upper and Lower Gas Sands were tested in KTL-1 and well KTL-6. Recently well KTL-7 has been drilled to the depth 3565 meter to recover oil resources from the field shown in Fig. 1 (http://www.sgfl.org.bd).

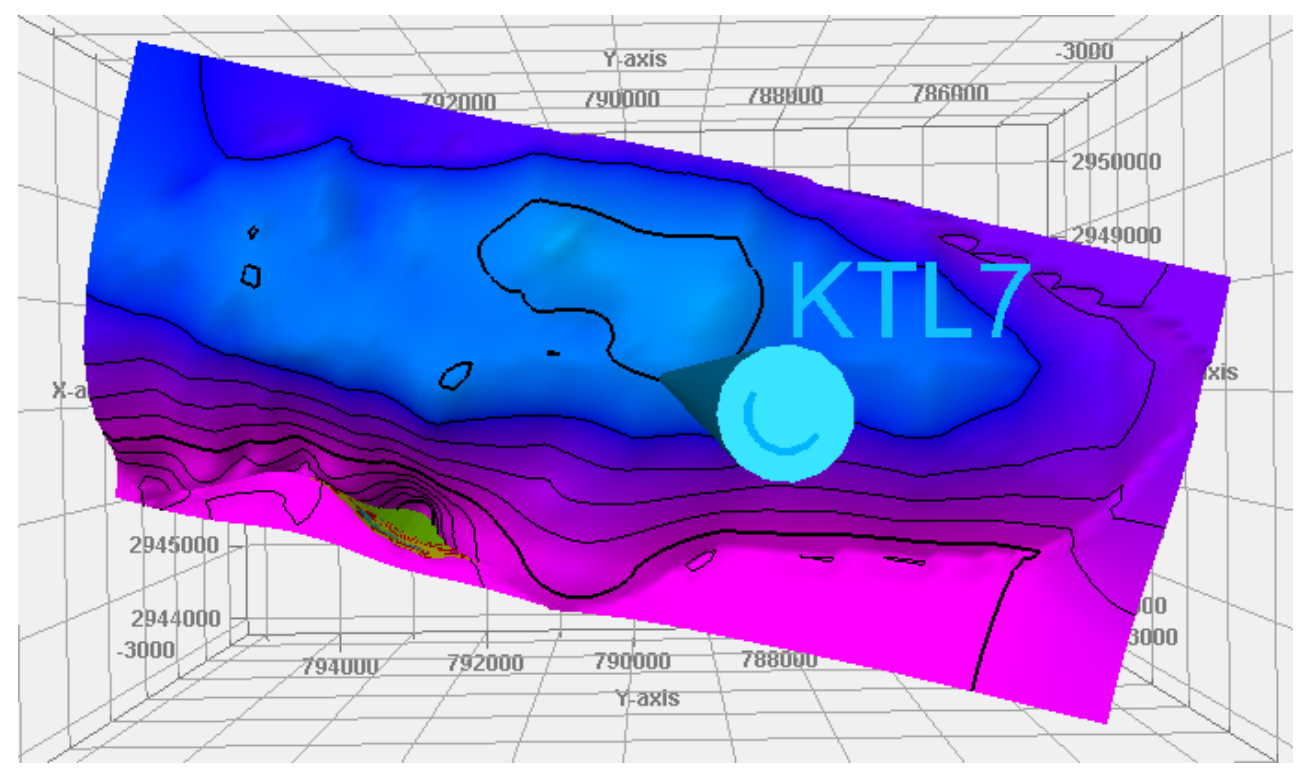

Fig. 1. Location of well KTL-7 in the reservoir.

\section{DST interval selection}

The DST interval is selected on the basis of the well log analysis. In the interval 3261 meter to 3266 meter, the log analysis shows that low value of gamma ray $\log$, high value of resistivity log with shallow and deep separation and high value of acoustic log indicating porous permeable formation with hydrocarbon bearing zone (Fig. 2). 


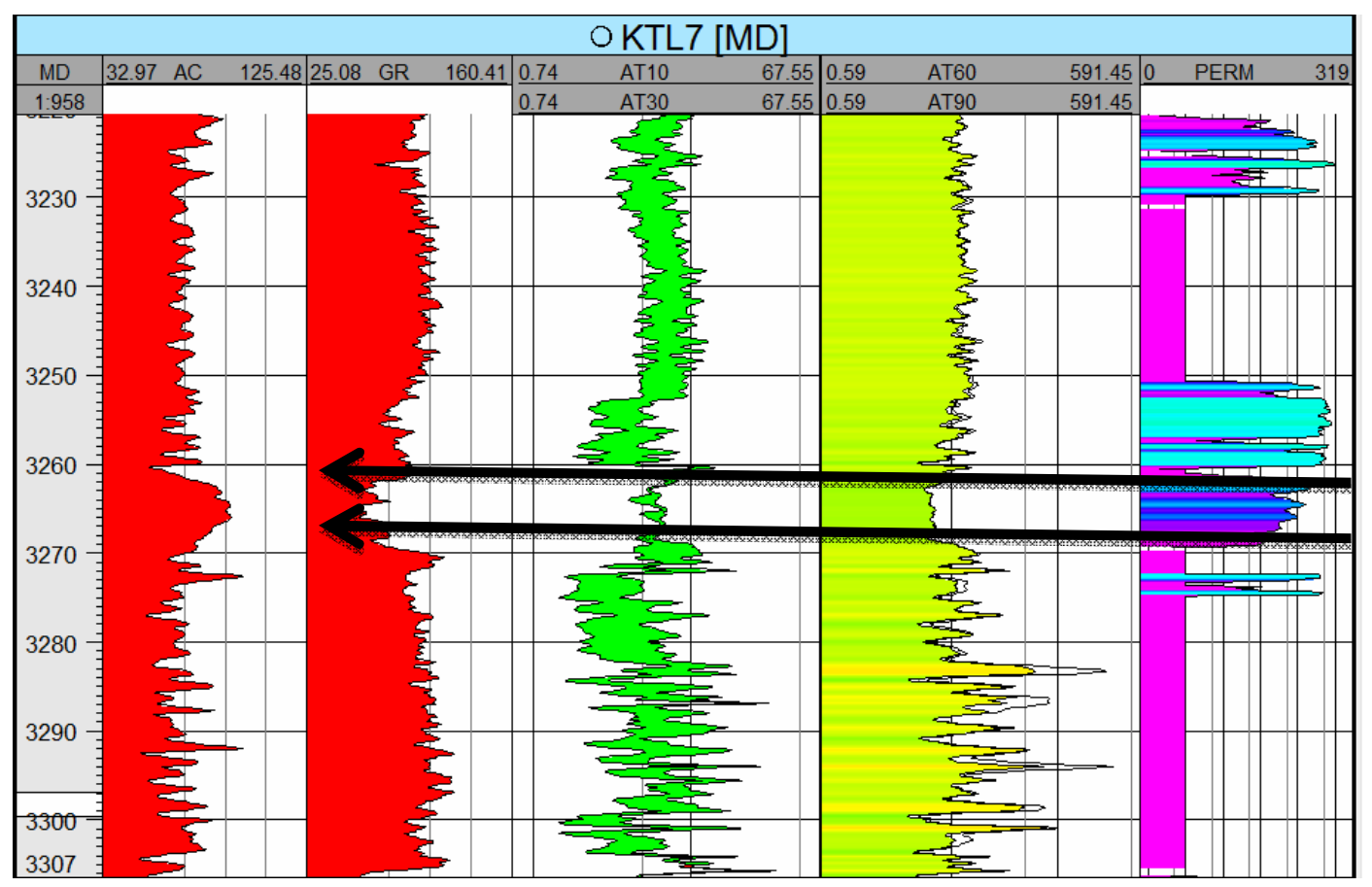

Fig. 2. Well logs in well KTL-7 and DST interval.

\section{Description of DST operation}

To conduct the safe and proper DST operation it is very important to design the DST string and the Bottom Hole Assembly (BHA) according to the collapse load, burst load and shear failure. The DST string and BHA are shown in Fig. 3 where drill pipe, drill collar, crossover, pressure gauge are used.

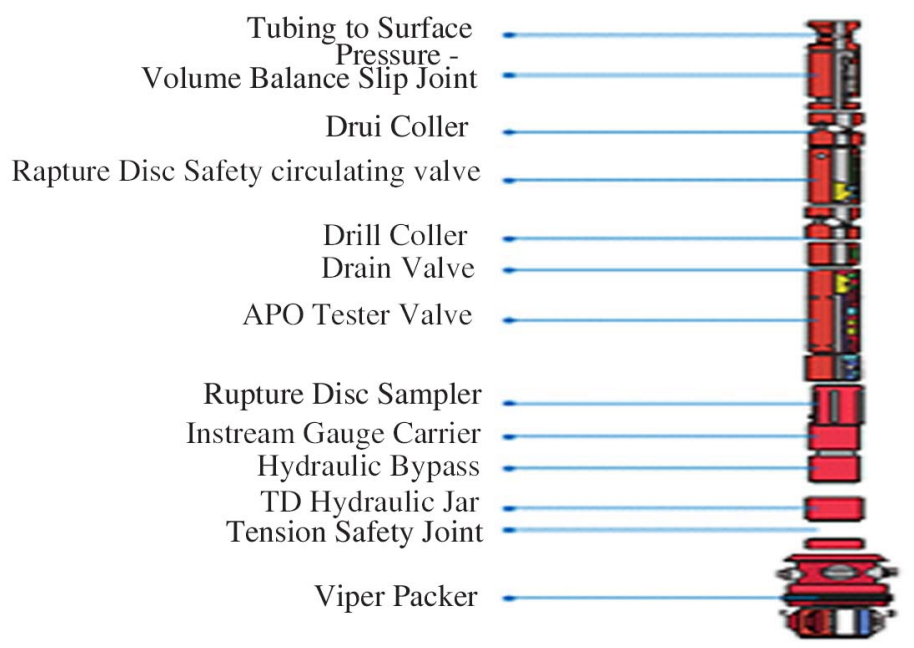

Fig. 3. DST string and BHA for DST operation. 
The DST operation commenced on 9th February 2015 at 18.00 hours and terminated on 12th February at 12.00 hours. Interval and surface pressure profile and liquid height profile are plotted over the entire test period shown in Fig. 4.

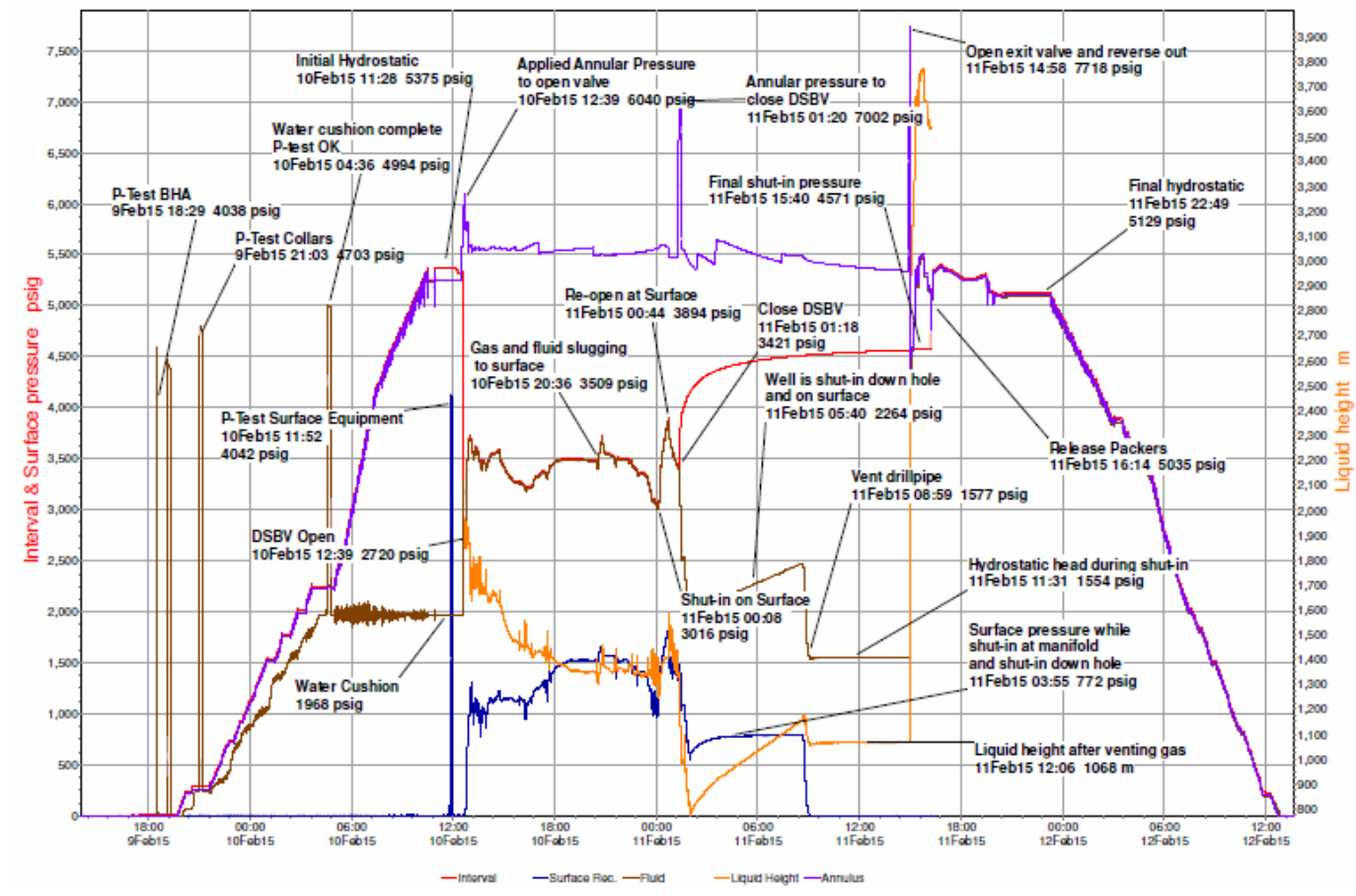

Fig. 4. Summary of DST operation.

During the total test period, first the well bore conditioning and pressure gauge calibration operation are performed in the initial hydrostatic period then started the drawdown period for 760 minutes following build-up period for 892 minutes shown in Table 1. Four pressure gauge and temperature recorder have been installed in the test stem for recording four sets of data. Two record numbers 1785 and 40914 have shown the reservoir responses in the pressure profile which have been analyzed.

Table 1. Summarized DST events.

\begin{tabular}{llllllll}
\hline & Recorder \#/depth (m) & & Surface & 1787 & 1788 & 1785 & 40914 \\
\hline & $\begin{array}{l}\text { Date/time } \\
\text { mm/dd hh:mm }\end{array}$ & $\begin{array}{l}\text { Duration } \\
(\mathrm{min})\end{array}$ & & 3226.67 & 3226.67 & 3239.50 & 3239.50 \\
& $02 / 1011: 18$ & & & & 5250 & 5375 & 5377 \\
\hline A. Init Hydrosatatic & $02 / 1012: 41$ & 760 & 22 & 1968 & 6094 & 2723 & 2724 \\
B. Start Flow 1 & $02 / 1101: 21$ & & 1480 & 3411 & 7047 & 3426 & 3427 \\
B. End Flow 1 & $02 / 1116: 12$ & 892 & 5 & 4913 & 4774 & 4574 & 4575 \\
C. End Shut in 1 & $02 / 1122: 19$ & & & 5089 & 5109 & 5128 & 5129 \\
M. End Hydrostatic & & & & & & & \\
\hline
\end{tabular}


The liquid flow profile is plotted during the DST operation. It has been observed that during the DST significant quantity of liquid has flown from reservoir into wellbore in form of oil and water in an average rate $300 \mathrm{~m}^{3} / \mathrm{d}$ shown in Fig. 5 .

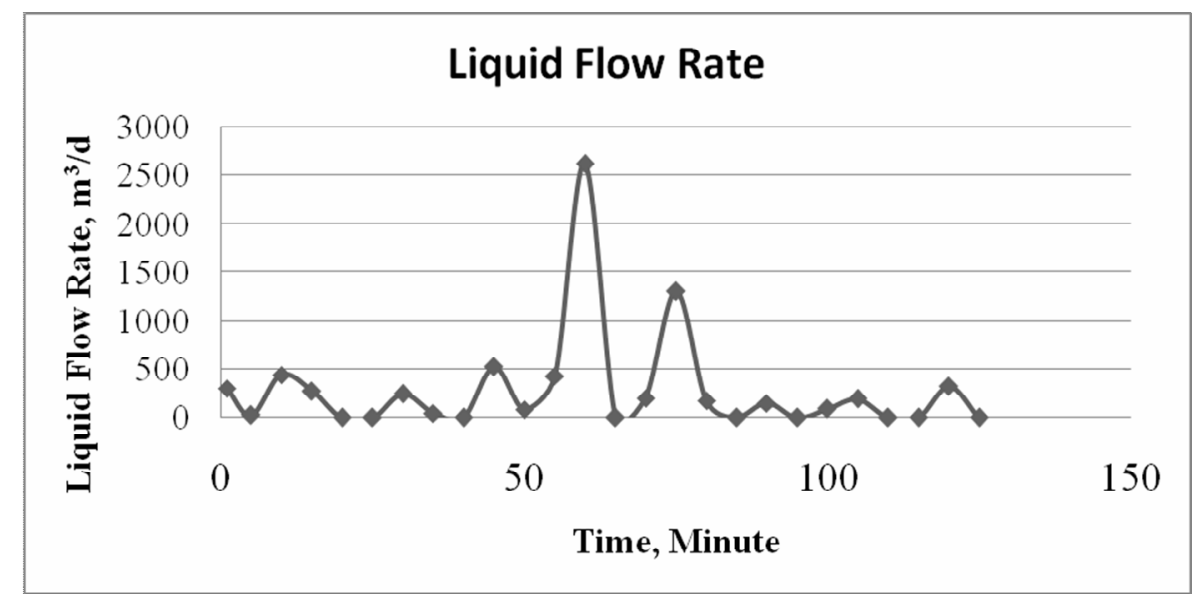

Fig.5. Liquid flow profile during DST.

Analysis of DST data for record numbers 1785 and 40914

A pressure gauge is set at the depth 3239.5 meter to record the flowing pressure during the DST operation and pressure signature is recorded under the record no. 1785. In the total pressure profile of the DST there is presence of drawdown following buildup pressure signature (Fig. 6) from 26.02 to $37.57 \mathrm{hrs}$ and from 37.57 to $53.68 \mathrm{hrs}$, respectively since the start of test.

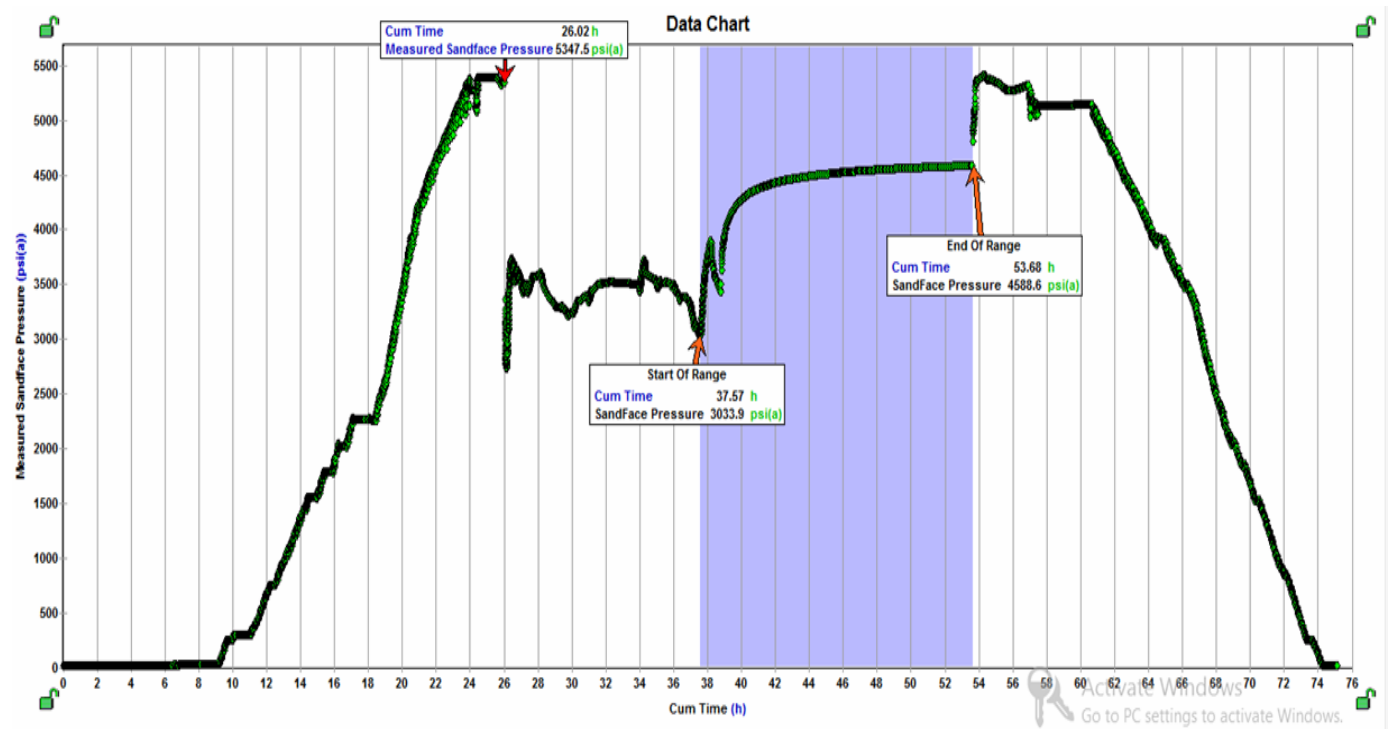

Fig. 6. Recorded total pressure profile of DST. 
The recorded total pressure data are filtered as per 300 data per cycle to remove the noise and develop the full test model of drawdown following buildup periods shown in Fig. 7. The drawdown period (tp) persists for 11.5514 hour and pressure buildup period $(\Delta t)$ exists for 16.1069 hour. The initial pressure ( $\mathrm{Pi}$ ) is 5347.53 psig and after drawdown the flowing pressure (Pwf) is 3033.92 psig following buildup period the pressure increases to 4588.57 psig.

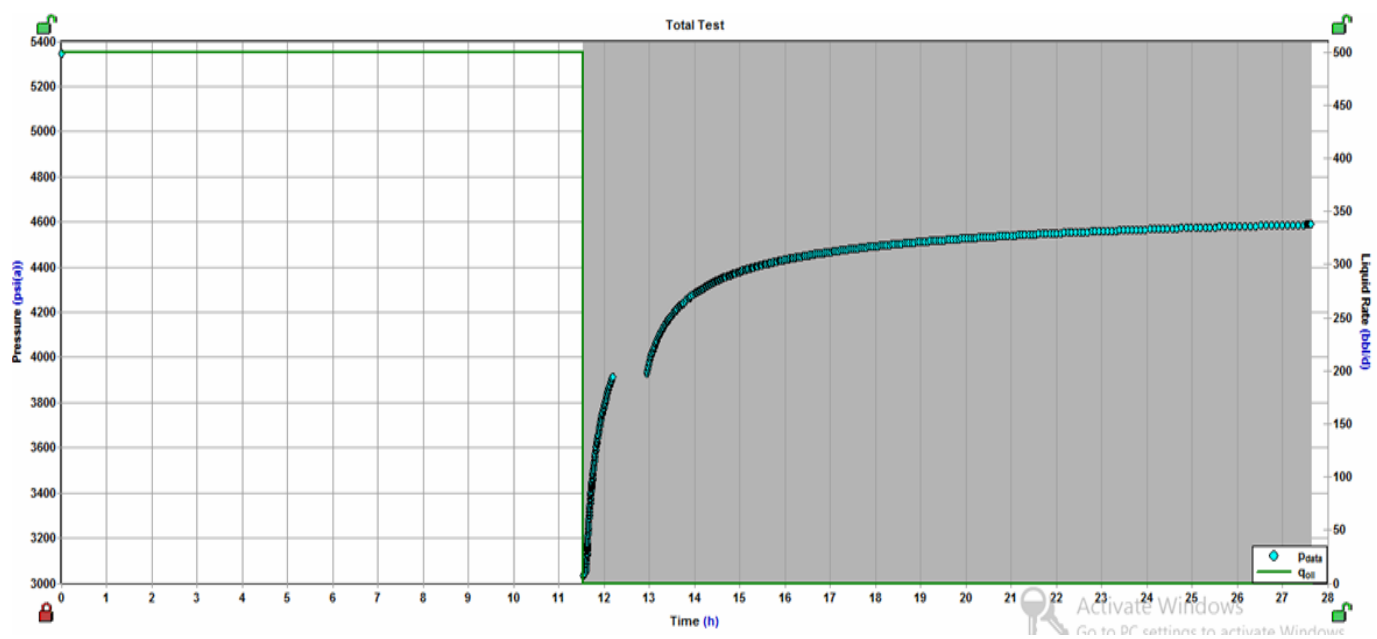

Fig. 7. Full test model of draw down following buildup period.

The shut-in pressure (Pws) is plotted in Cartesian scale and the Horner time $[(t p+\Delta t) / \Delta t]$ is plotted in $\log$ scale to build a semi-log plot of buildup test. A best fitted straight line is drawn along the data points to estimate the slope and intersection of the straight line. From the slope of the straight line permeability $(\mathrm{k})$ is calculated 6.3312 millidarcy $(\mathrm{md})$ and from the intersection the average reservoir pressure ( $\mathrm{p}^{*}$ ) is calculated 4858.8 psia (Fig. 8).

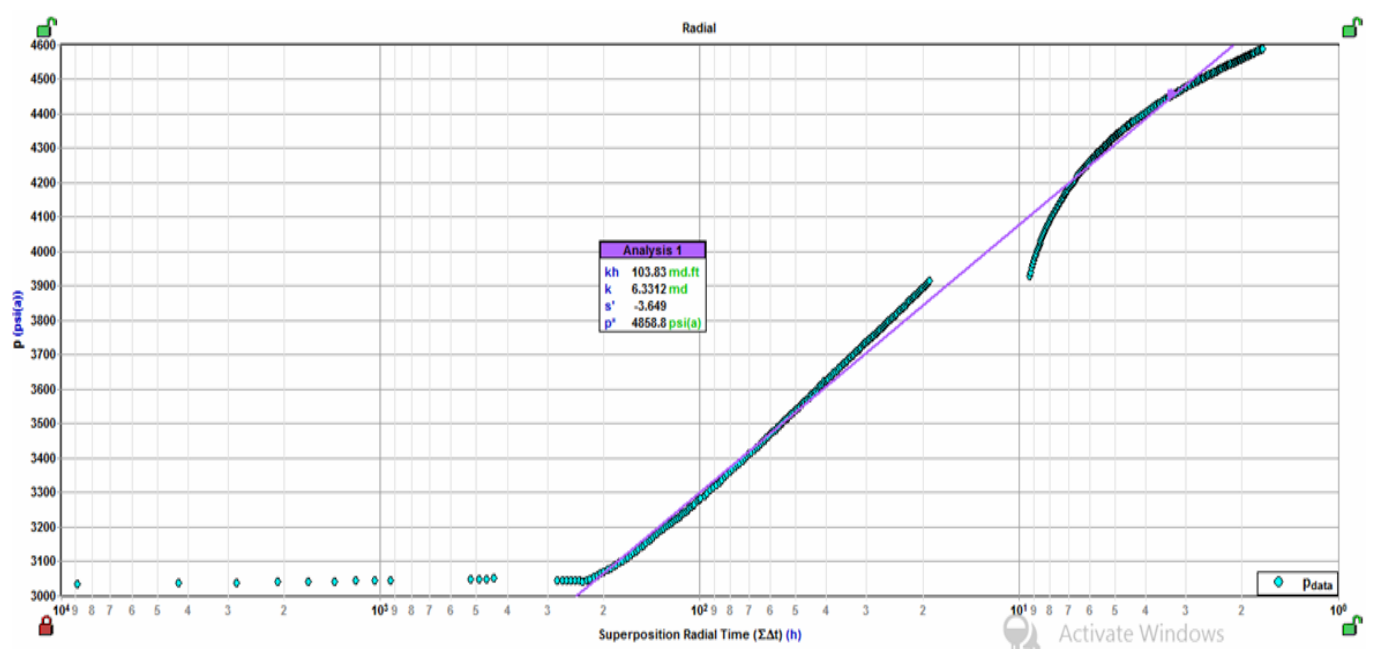

Fig. 8. Semi log plot of buildup test. 
The buildup pressure $(\Delta \mathrm{Pbu}=\mathrm{Pws}-\mathrm{Pwf})$ and its derivative $[\mathrm{d} \Delta \mathrm{Pbu} / \mathrm{d}(\mathrm{tp}+\Delta \mathrm{t}) / \Delta \mathrm{t}]$ is plotted in log scale along the Horner time $[(\operatorname{tp}+\Delta \mathrm{t}) / \Delta \mathrm{t}]$ in the same scale to build the diagnostic plot shown in Fig. 9 where well bore storage effect, skin effect and infinite acting reservoir responses are visible clearly. The well bore storage is $0.21 \mathrm{bbl} / \mathrm{psi}$ and from the infinite acting line the permeability is $6.3312 \mathrm{md}$.

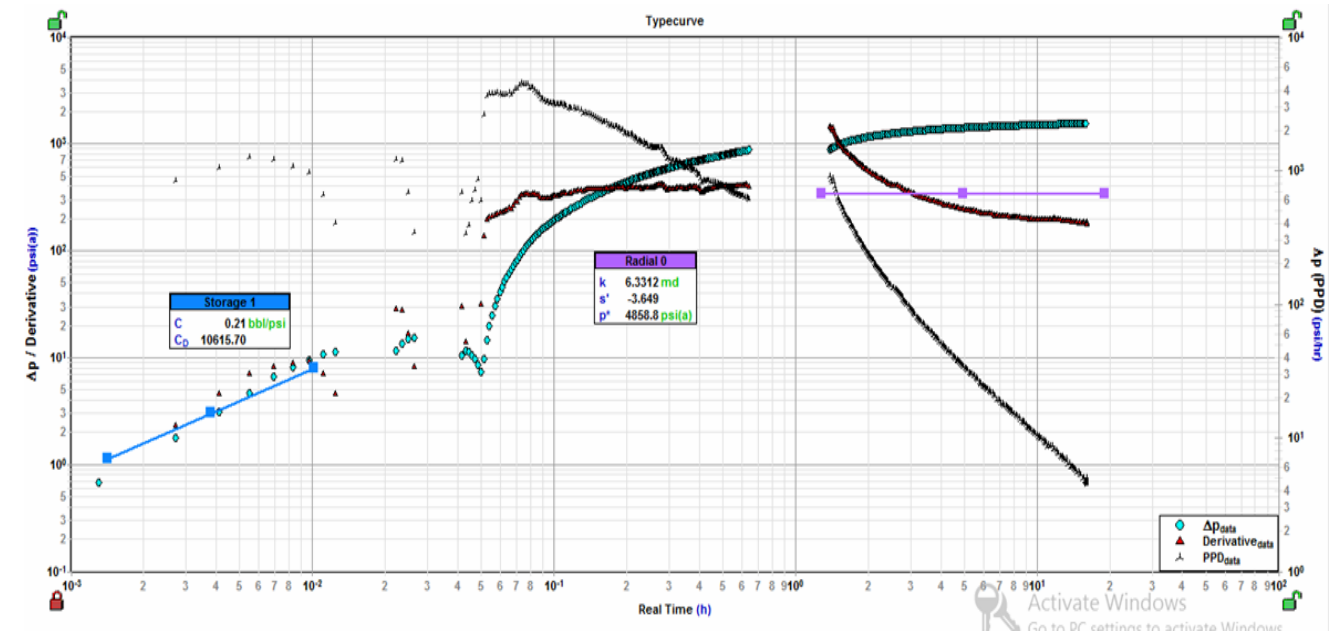

Fig. 9. Diagnostic plot of buildup test.

Another pressure gauge is set at the depth 3239.5 meter to record the flowing pressure during the DST operation and pressure signature is recorded under the record no. 40914. In the total pressure profile of the DST there is presence of draw down following buildup pressure signature shown in Fig. 10 from 25.88 to $37.60 \mathrm{hrs}$ and from 37.60 to $53.59 \mathrm{hrs}$, respectively since the start of test.

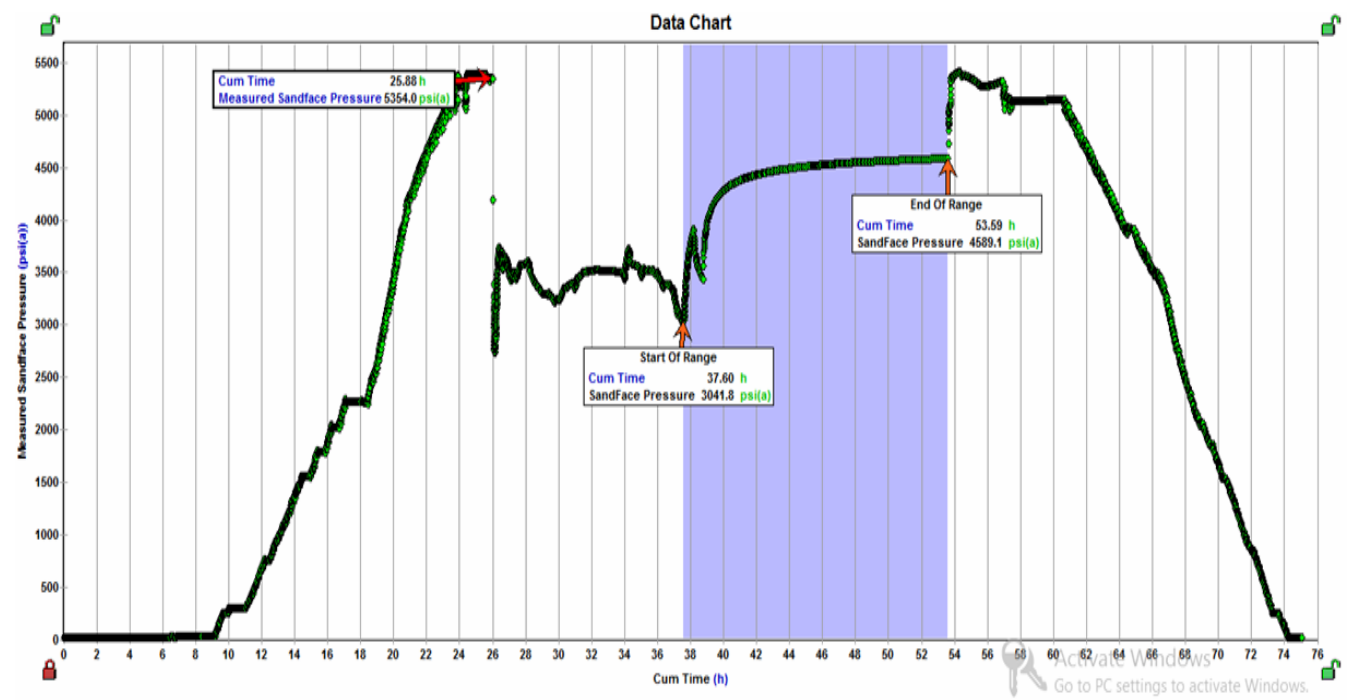

Fig. 10. Recorded total pressure profile of DST. 
The recorded total pressure data is filtered as per 400 data per cycle to remove the noise and develop the full test model of drawdown following buildup periods shown in Fig. 11. The drawdown period (tp) persists for 11.5986 hour and pressure buildup period $(\Delta t)$ exists for 15.9848 hour. The initial pressure $(\mathrm{Pi})$ is 5348.83 psig and after drawdown the flowing pressure (Pwf) is 3041.79 psig following buildup period the pressure increases to 4589.14 psig.

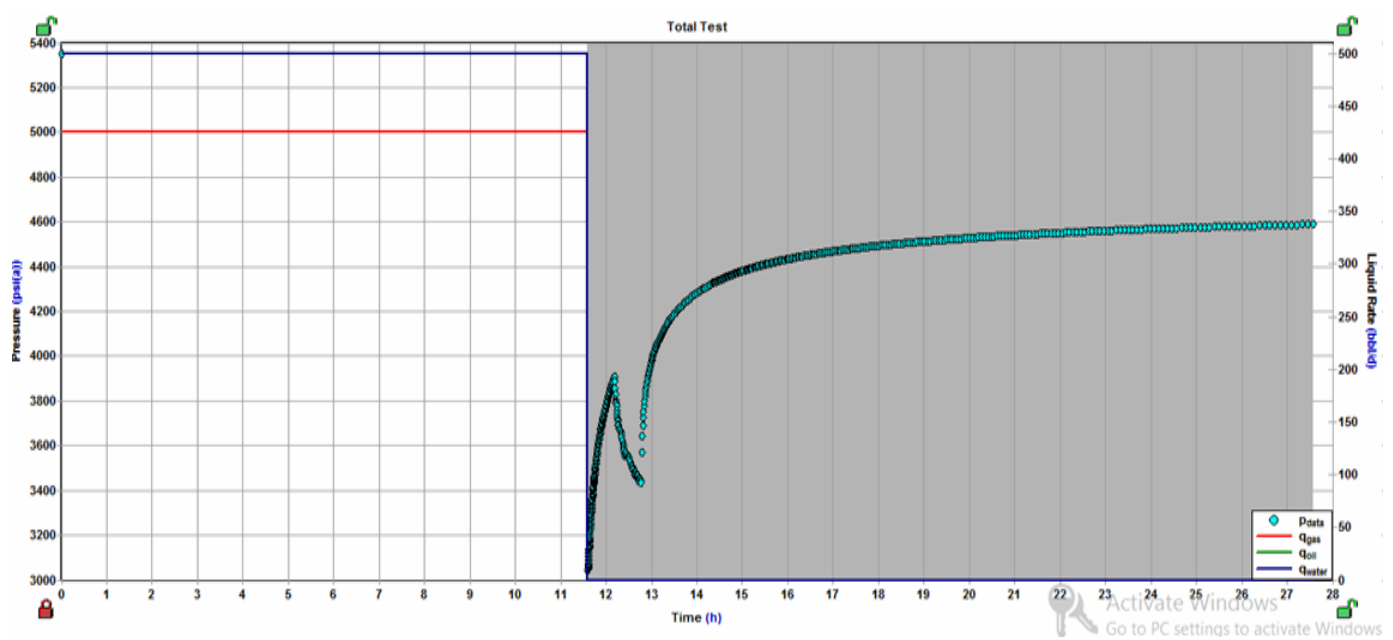

Fig. 11. Full test model of drawdown following buildup period.

The shut-in pressure (Pws) is plotted in Cartesian scale and the Horner time $[(\mathrm{tp}+\Delta \mathrm{t}) / \Delta \mathrm{t}]$ is plotted in log scale to build a semi-log plot of buildup test. A best fitted straight line is drawn along the data points to estimate the slope and intersection of the straight line. From the slope of the straight line permeability $(\mathrm{k})$ is calculated 12.2179 millidarcy $(\mathrm{md})$ and from the intersection the average reservoir pressure ( $\mathrm{p}^{*}$ ) is calculated 4834.7 psia (Fig. 12).

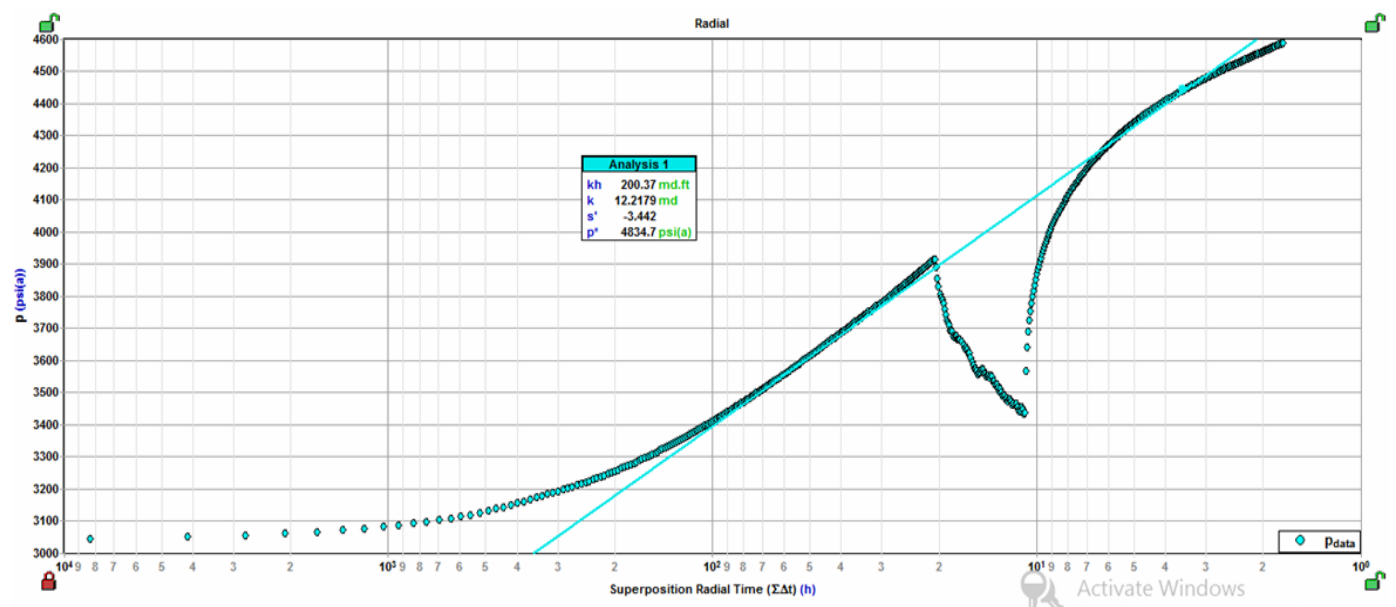

Fig. 12. Semi-log plot of buildup test. 
The buildup pressure $(\Delta \mathrm{Pbu}=\mathrm{Pws}-\mathrm{Pwf})$ and its derivative $[\mathrm{d} \Delta \mathrm{Pbu} / \mathrm{d}(\mathrm{tp}+\Delta \mathrm{t}) / \Delta \mathrm{t}]$ is plotted in $\log$ scale along the Horner time $[(\operatorname{tp}+\Delta \mathrm{t}) / \Delta \mathrm{t}]$ in the same scale to build the diagnostic plot shown in Fig. 13 where well bore storage effect, skin effect and infinite acting reservoir responses are visible clearly. The well bore storage is $0.04 \mathrm{bbl} / \mathrm{psi}$ and from the infinite acting line the permeability is $12.2179 \mathrm{md}$.

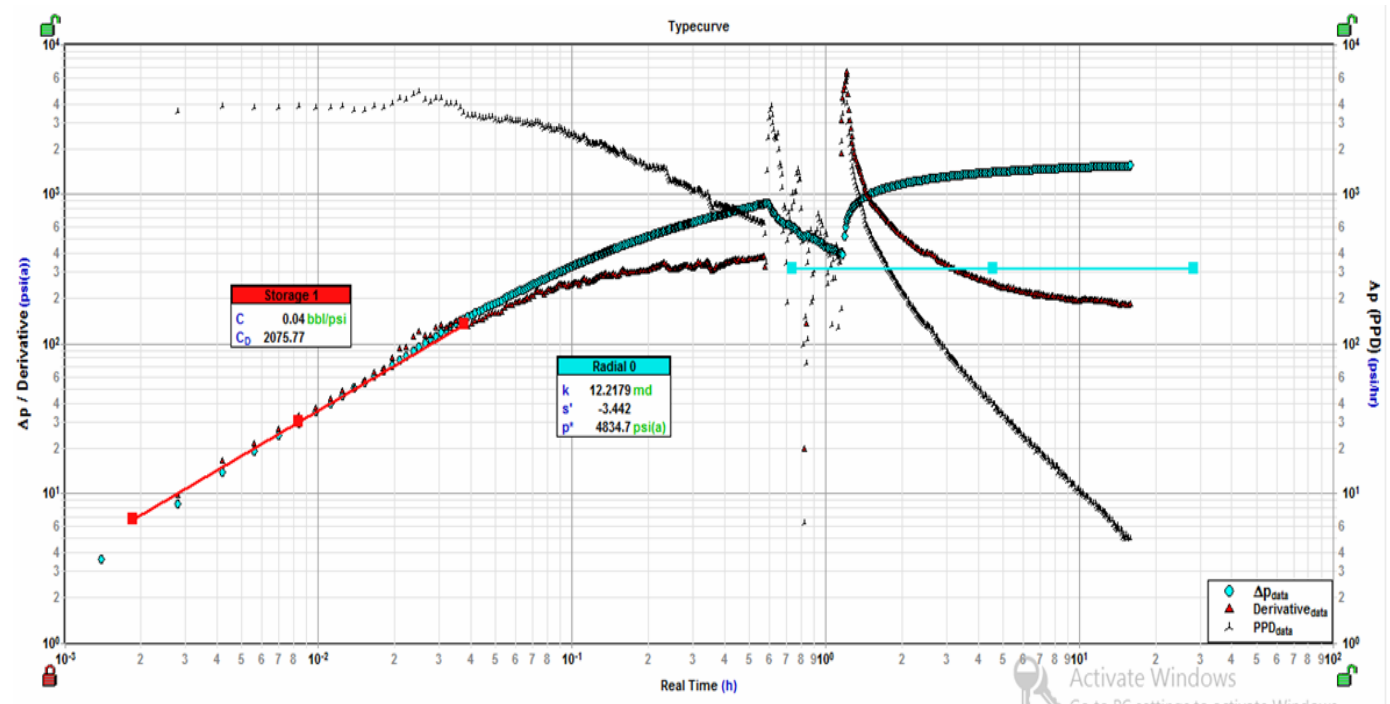

Fig. 13. Diagnostic plot of buildup test.

\section{Results}

The well test analysis is an authentic technology to detect and characterize the hydrocarbon bearing formation. In the DST there are two records which have shown the reservoir responses in the pressure signature. These two pressure profiles are analyzed as per the standard well test analysis technique such as semi-log and diagnostic plot analysis which reveal the existence of the petroleum reservoir of the characteristics in Table 2.

Table 2. Summary of DST interpretation.

\begin{tabular}{|c|c|c|c|}
\hline Parameter & \multicolumn{2}{|l|}{ Value } & Remarks \\
\hline Interval & \multicolumn{2}{|c|}{3261 to $3266 \mathrm{~m}$} & $\begin{array}{l}\text { According to the well logs in that interval there is a } \\
\text { porous and permeable formation. }\end{array}$ \\
\hline \multirow{3}{*}{$\begin{array}{l}\text { Effective } \\
\text { Permeability }(\mathrm{K}) \text {, } \\
\mathrm{mD}\end{array}$} & Re. No. & Re. No. & Permeability is low. \\
\hline & 1785 & 40914 & \multirow[t]{2}{*}{ Consistent with DST value. } \\
\hline & 6.3312 & 12.2179 & \\
\hline \multirow[t]{2}{*}{ Skin factor $(S), D L$} & $\begin{array}{l}\text { Re. No. } \\
1785\end{array}$ & $\begin{array}{l}\text { Re. No. } \\
40914\end{array}$ & Skin Factor is negative. \\
\hline & -3.649 & -3.442 & $\begin{array}{l}\text { Negative skin factor indicating that there are fractures } \\
\text { developed near the well bore during drilling operation. }\end{array}$ \\
\hline
\end{tabular}




\begin{tabular}{|c|c|c|c|}
\hline \multirow{3}{*}{$\begin{array}{l}\text { Wellbore storage, } \\
\mathrm{C}, \mathrm{bbl} / \mathrm{psi}\end{array}$} & Re. No. & Re. No. & \multirow{3}{*}{$\begin{array}{l}\text { Wellbore storage is low. } \\
\text { Low wellbore storage indicates that liquid has flown } \\
\text { from reservoir into well bore. }\end{array}$} \\
\hline & 1785 & 40914 & \\
\hline & 0.21 & 0.04 & \\
\hline \multirow{3}{*}{$\begin{array}{l}\text { Average reservoir } \\
\text { pressure, } \mathrm{P}^{*} \text {, psia }\end{array}$} & Re. No. & Re. No. & Average reservoir pressure is high. \\
\hline & 1785 & 40914 & Water column pressure at depth $3266 \mathrm{~m}$ is 4647 psia. \\
\hline & 4858.8 & 4834.7 & $\begin{array}{l}\text { Approximately } 200 \text { psi overpressure exists in the zone } \\
\text { which indicates the existence of oil. }\end{array}$ \\
\hline \multirow[t]{5}{*}{ Boundaries } & Re. No. & Re. No. & No boundaries have been developed. \\
\hline & 1785 & 40914 & No interference with other wells in the field. \\
\hline & Infinite & Infinite & No fault in the drainage area. \\
\hline & acting & acting & No channel in the drainage area. \\
\hline & & & No fracture in the drainage area. \\
\hline
\end{tabular}

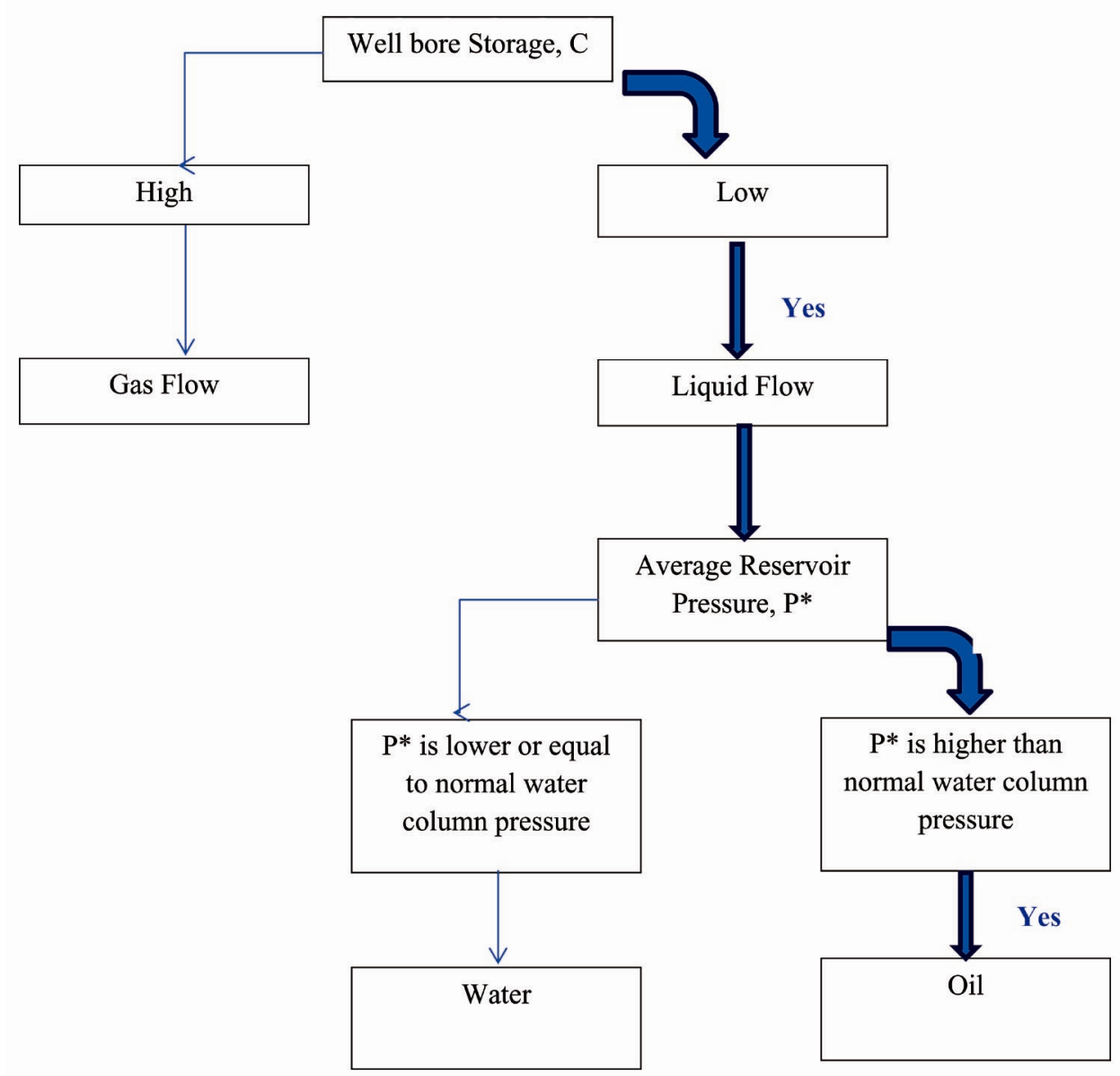

Fig. 14. Decision flow chart on the basis of DST analysis. 


\section{Conclusion}

The analysis of pressure signature obtained from the DST the wellbore storage, skin factor, permeability and average reservoir pressure have been estimated and their values are analyzed to obtain the following:

1. The flowing phase during the DST is liquid on an average rate $1000 \mathrm{bbl} / \mathrm{d}$.

2. Although the reservoir permeability is low, the negative skin factor helps the reservoir liquid to flow into the wellbore.

3. The low value of wellbore storage provides the evidence of the presence of liquid phase has flown into the well bore from the reservoir. There is no flow of gas phase into the wellbore from the reservoir.

4. Average reservoir pressure and water column pressure at depth $3266 \mathrm{~m}$ reveals the existence of the over pressure zone which is developed by the presence of hydrocarbon in liquid phase.

5. Well $\log$ analysis i.e. low value of gamma ray log and high value of resistivity log with shallow and deep resistivity separation indicates the presence of hydrocarbon as well.

From the above analysis it can be concluded that all of the investigations i.e. well logs and DST analysis are able to provide the evidence of the presence of liquid hydrocarbon (oil) in the interval 3261 to 3266 meter. The decision flow chart of the analysis is shown in Fig. 14.

\section{References}

Earlougher, R.C. Jr. 1977. Advances in Well Test Analysis, Monograph Series no. 5, Society of Petroleum Engineers of AIME, Dallas.

Ehlig Economides, C.A., J.A. Joseph, R.W. Ambrose Jr. and C. Norwood. 1990. A modern approach to reservoir testing. J. Pet. Tech. II: 1554-1563.

Gringarten, A.C., D.P. Bourdet, P.A. Landel and Kniazeff. 1979. A comparison between different skin and wellbore storage type-curves for early-time transient analysis, Paper Society of Petroleum Engineers 8205.

Miller, C.C., A.B. Dyes and C.A. Hutchinson. 1950. Estimation of permeability and reservoir pressure from bottom-hole pressure build-up characteristics, Trans. AIME 189: 91-104.

Ramey, H.J.,Jr. 1992. Advances in practical well-test analysis. J. Pet. Tech. III: 650-659

Web Resources:

http://www.sgfl.org.bd

(Manuscript received on 10 May, 2016; revised on 17 August, 2016) 